\title{
Comunidad europea: los reglamentos y leyes sobre la competencia y el proteccionismo*
}

Para evitar la repetición de todos los errores cometidos en el sector de la agricultura europea es totalmente necesaria, una politica competitiva en el mercado interior, así como una politica comercial abierta a los mercados exteriores.

\section{Por el Dr. Franz Schoser* *}

El mercado europeo está de actualidad.

Me planteo la cuestión de saber cuáles serian los modelos de política económica que deberian servir en el marco de esta integración económica y social. Puede que en Alemania sintamos en gran manera un déficit en este ámbito ya que durante los últimos decenios hemos sostenido siempe una discusión acalorada en cuanto a los problemas de politica económica. Por ejemplo, en 1948, cuando introducimos en nuestro pais el concepto de mercado social o de economía social de mercado. Más tarde, igualmente, estas discusiones se produjeron y ciertamente que Alemania pudo también influir sobre ciertos debates en otros paises.

La cuestión está, pues, planteada. ¿Cómo debe presentarse la Europa de 1992, desde el punto de vista político y económico, y desde la perspectiva de la politica de orden económico?.

* Comunicación presentada por su autor en la Conferencia Europea de la Unión Internacional Cristiana de Dirigentes de Empresa (UNIAPAC), celebrada en Aquisgrán los dias 23 y 24 de septiembre de 1988.

" " Director General, "Deutscher Industrie-und Handelstag" (DIHT), Colonia. 
En primer lugar, no hay probablemente muchas alternativas - yo no las veo- a este mercado único de 1992. Todas las experiencias del mercado nos demuestran que los mercados abiertos, los mercados competitivos, son los mejores marcos para permitir una expansión económica. Esto es ciertamente válido.

Pero es un objetivo inalcanzable de manera automática. No cae por su propio peso, y así, pues, es ciertamente necesario que una competencia que funcione sea asegurada en el marco de una politica de la competencia y de un status jurídico que circunscriba las condiciones de esta competencia. Existe, por otra parte, esta responsabilidad de la Comunidad de los Doce, cara a terceros paises y, por ello, sería preciso que dentro de la idea del libre cambio no hubiese compartimentación de esta economia de mercado.

\section{La ventaja de las fronteras abiertas}

Desde el punto de vista del empresario, tal vez nunca hemos estado muy a favor de esta apertura de fronteras, ya que ello ha producido, igualmente, unos perjuicios. $Y$ hay, además, otros ejemplos. Basta con observar al Japón para ver cómo la política económica es llevada por este pais. Pero creo que para los europeos en general, la apertura debe ser, también, una voluntad ética, ya que icómo quieren Vds. que los paises del tercer mundo, especialmente, puedan conocer una expansión si les abandonamos a su propia suerte, y si cerramos la Comunidad de los Doce?.

La desaparición de las fronteras nacionales y las libertades que de ello resultarán no deben tener como consecuencia que se produzcan medidas y prácticas inmorales en el marco de la competencia. Es necesario, pues, prever un cierto número de normas. Tenemos ya la prohibición del cártel, en Alemania y en Europa. Blen; esta prohibición de los cárteles en Europa es una cosa importante, algo justificado, especialmente cuando se puede exigir por parte de los empresarios racionalizaciones $u$ otras medidas que permitan una producción creciente, que permitan un trabajo y una actividad económica más favorable. Esto es también importante en el campo de la investigación en común; e igualmente importante cuando existe fusión por razones válidas.

Hay un segundo principio, es el articulo 85 , que prohibe la utilización de posiciones monopolisticas sobre el mercado. Sabemos que los padres del Tratado de Roma habian previsto unas posibilidades para los gobiernos, en cuanto a controlar a las empresas en posición de monopolio. $Y$ he aqui que los controles de las fusiones que se han realizado desde 1973, en el marco del derecho europeo sobre cárteles, 


\section{Competencia y proteccionismo en la CEE}

no han sido todavia previstos. Todas las personas que se han preocupado de ello saben que hoy dia se discute en profundidad, desde que ciertos Estados miembros se han opuesto a esta voluntad juridica. $\mathrm{Se}$ desea realizar este dispositivo legal. Se desea que este dispositivo legal sea aplicable a todas las entidades económicas europeas y ello en el ámbito de este mercado único, para evitar que haya grupos de monopolio.

Evidentemente, estas discusiones son difíciles. Hoy día, se puede decir, en general, que el derecho competitivo se ha convertido en un campo de juristas altamente especializados, ya que los términos, los conceptos, son difíciles y complejos. Lo digo de manera crítica, estos términos no prestan siempre suficiente atención a aspectos que pertenecen, sin embargo, a la realidad económica.

Para los participantes alemanes, el aspecto que voy a mencionar es quizá más importante que para los demás. Es preciso saber que nuestro debate alemán en torno al derecho de los cárteles se amplia de dia en dia, ya que en otros paises también se ha comenzado a plantear la cuestión de las economias de escala. Es cierto que hasta ahora se podia permanecer con la vista puesta en los mercados nacionales. Ahora bien, desde que hablamos de un mercado único, es necesario, en el contexto de una previsión y de un reglamento de las concurrencias y de la competencia en Europa, hablar, igualmente, de esta economia de escala. La tentativa de evitar la posición monopolista debe prever, del mismo modo, este aspecto. En este sentido creo que la integración de los mercados se acompaña de la creación de instrumentos importantes, que, no obstante, no pueden ser solamente un obstáculo para la integración de unidades económicas. Pero el gran objetivo debe ser siempre y seguir siéndolo que la competencia en el marco del mercado único de toda Europa no sea limitada.

Europa en proceso de integración, una Europa que ve sus intereses en una integración politica y económica, una tal Europa y un tal proceso $-y$ esto es de hecho lógico cuando se crea un mercado único- hacen que, de forma inconsciente o consciente, se cierren las fronteras a terceros. $\mathrm{O}$, si lo formulamos de otra manera, frente a los Estados Unidos por ejemplo, frente al Japón igualmente y después, mucho más cerca de nosotros, frente a los paises europeos que no forman parte de la Comunidad, tales como los paises de la AELE. En todos estos paises se tiene la preocupación de que esta integración europea se haga a costa de los demás. Un eslogan como la ufortaleza europea" - se trata de un eslogan formulado en el exteriorexplica de una forma explicita, a mi entender, muy bien esta preocupación y desvelo. 
Puede que, por el lado americano, la mala conciencia juegue un cierto papel, la mala conciencia que contiene quizá la voluntad de hacer olvidar un poco a los demás las medidas proteccionistas que los Estados Unidos aplican, por su parte, desde hace tiempo. pero, aunque esto sea una realidad, tenemos el deber y la responsabilidad co. mo Comunidad Europea de permanecer lo más abiertos posibles frente a terceros países.

Desde el punto de vista alemán, y creo que ello corresponde al punto de vista europeo, diría yo que las preocupaciones de los otros tienen su razón de ser. Ello no es solamente cierto en el área de la agricultura. Es necesario decir, que la competencia de la Comunidad Europea, sobre todo de la Comisión en Bruselas, en lo que se refiere a las cuestiones de política comercial, va en aumento. La integración que se realiza cada vez más hará que se produzcan cada vez más reglas, unas leyes que harán que desaparezcan las diferencias entre las normas comerciales existentes todavia en la actualidad en los diferentes paises. Asi pues, se trata de ponerlo todo bajo un denominador común. Si hablo de contingentes comunitarios, si hablo de acuerdo de autolimitación o si hablo de otros acuerdos que se han realizado y establecido para resolver los problemas comerciales, todo esto es buena prueba de lo que afirmo.

Existen áreas, digamos de sensibilidad especial, como la del textil, y también las del metal, la construcción o fabricación automovilística y otras. Para estos sectores existen normas que deseariamos cambiar. Especialmente los alemanes desearian cambiar algunas. La contingentación en el sector del automóvil, por ejemplo, es un problema. Nos planteamos la cuestión de saber cómo se presentarán estas normas de restricción en el futuro, pero ello puede extenderse a otras medidas de protección menos abiertas. En la actualidad existe el término de ureciprocidad" que intenta fijar estas posibilidades. Hay todo el sector de servicios. Así pues, los servicios, el sector de los servicios, es un término demasiado amplio. No es posible, efectivamente, reducir toda la complejidad de este sector a un sólo término y a una sola serie de reglas, de leyes, de reglamentos.

Creo que todos los amigos europeos estarán de acuerdo en declarar que es preciso hacer lo imposible para que este mercado único no constituya un mercado cerrado cara al exterior. Es necesario, efectivamente, que este mercado esté abierto al exterior $y$, sobre todo, evitar la repetición de todos los errores cometidos en el sector de la agricultura. Y justamente, creemos, que la politica competitiva para asegurar todo ello es totalmente necesaria en el interior, tanto como una política comercial abierta al exterior. 